\title{
Comparison of the Alkali-Silica Reactivity of North Cyprus and South Cyprus aggregates; preliminary studies using RILEM method
}

\author{
Pinar Akpinar ${ }^{1}$, and Andisheh Zahedi ${ }^{2 *}$ \\ ${ }^{1}$ Civil Engineering Department, Near East University, Nicosia, North Cyprus, Mersin 10, Turkey \\ ${ }^{2}$ Civil Engineering Department, University of Ottawa, Ottawa, Canada
}

\begin{abstract}
Alkali-silica reaction (ASR) is regarded as one of the most deleterious concrete durability problems, known to cause severe deteriorations in reinforced concrete structures all around the world. ASR involves the reaction of alkaline concrete pore solution with silica minerals in the aggregates and as a result, hydrous alkali-silica gel is produced. Expansion caused by this gel upon absorbing moisture results in serious deterioration in concrete. Although the susceptibility of South Cyprus aggregates to ASR has been previously studied to a very limited extent in the past, no scientific information on the ASR susceptibility of North Cyprus aggregates are available in the related literature. Bessparmak (Pentadaktylos) Mountains (North Cyprus) and from Troodos Mountains (South Cyprus) are positioned close to each other; however, aggregates obtained from both mountains are known to differ in composition. This difference in composition has the potential to yield ASR performances varying significantly. The aim of this study was to carry out preliminary investigations on the alkali-silica reactivity performance of both North and South Cyprus aggregates under same conditions, in a systematic and comparative manner. Aggregates obtained from both mountains are tested in combination with CEM I and CEM II (with supplementary cemenetitious materials) under the exposure conditions of RILEM method AAR-2. Preliminary results showed that North Cyprus aggregates are potentially reactive when used with CEM II, where South Cyprus aggregates tested under same conditions are detected to have much higher levels of reactivity.
\end{abstract}

\section{Introduction}

Alkali-silica reaction is a reaction between alkaline pore solution and silica minerals like cryptocrystalline quartz and opal present in aggregates. Pore solution of concrete contains potassium $\left(\mathrm{K}^{+}\right)$and sodium $\left(\mathrm{Na}^{+}\right)$ions and hydroxyl ions $\left(\mathrm{OH}^{-}\right)[1,2]$. In the highly basic environment of concrete microstructure, the hydroxyl ions $\left(\mathrm{OH}^{-}\right)$attack the $\mathrm{Silanol}(\mathrm{Si}-$ $\mathrm{OH})$ and Siloxane $(\mathrm{Si}-\mathrm{O}-\mathrm{Si})$ groups of reactive silica and yield the reaction given in the following equations $[3,4]$ :

$$
\begin{gathered}
\mathrm{Si}-\mathrm{OH}+\mathrm{OH}^{-}+\mathrm{Na}^{+} \rightarrow \mathrm{Si}-\mathrm{O}-\mathrm{Na}+\mathrm{H}_{2} \mathrm{O} \\
\mathrm{Si}-\mathrm{O}-\mathrm{Si}+2 \mathrm{OH}^{-}+2 \mathrm{Na}^{+} \rightarrow 2(\mathrm{Si}-\mathrm{O}-\mathrm{Na})+\mathrm{H}_{2} \mathrm{O}
\end{gathered}
$$

Under this attack, microcrystalline quartz with other aggregate particle form a viscous and hygroscopic gel called "alkali- silica gel" [5,6]. This gel absorbs water and expands in moist areas. The expansive pressure by the silica gel causes cracking and deteriorations in concrete [7].

The likelihood of ASR occurrence in concrete made with South Cyprus aggregates had been studied only in a limited extent and presented in previous studies [8,9]. On the other hand, there is no scientific information on the level of alkali silica reactivity of North Cyprus aggregates available in the related literature, since ASR concept has not been previously studied in North Cyprus.

This study aims to provide experimental results on the alkali-silica resistance of both North and South Cyprus aggregates in a systematical and comparative manner. Beşparmak (Pentadaktylos) Mountains (North Cyprus) and from Troodos Mountains (South Cyprus) are positioned close to each other; however, aggregates obtained from both mountains are known to differ in composition. This difference in composition has the potential to yield significantly varying ASR performances.

\section{Experimental Procedure}

The RILEM method "Ultra-accelerated Mortar Bar Testing" (AAR-2) [10] was employed for testing the level of reactivity of aggregates used in this study. This RILEM method of testing has the advantages of proposing a viable procedure with clearly specified expansion limits defined in the related literature based on extensive previous

\footnotetext{
*Corresponding author: azahe049@uottawa.ca
} 
experience [11], which serve to classify level of reactivity easily and effectively. In addition to these, its relatively short testing period required to provide the results makes AAR-2 to be commonly preferred as a first step in investigating the reactivity of aggregates by research carrying out studies in this field.

This test method basically involves preparation of mortar bars having the dimensions of $25 \mathrm{~mm} \times 25 \mathrm{~mm} 285 \mathrm{~mm}$, with cement: fine aggregate and water/cement ratios defined to be $1: 2.25$ and 0.47 , respectively.

Three mortar bars were prepared for each batch and the length change observed in these bars under the exposure conditions suggested by the method was recorded systematically through out the testing period.

\subsection{Sample Preparation and Materials}

The types of aggregates that are known to be commonly used in concrete industries of South and North Cyprus were selected for this study, in order to be able to provide representative results for existing buildings in both sides of the island. "Crystallized dolomitic limestone" aggregates obtained from the quarries of Beşparmak (Pentadaktylos) Mountains in North Cyprus were obtained with the help of North Cyprus Geology and Mines Department, where "diabase" aggregates from Pirga quarry of Troodos Mountains were obtained with the help of Geological Survey Department of South Cyprus. The aggregates were sieved and prepared to have a particle size distribution between 4.75 to 0.15 as proposed in the AAR-2 method.

Weights of constituents needed for each batch of 3 mortar bars according to the AAR-2 was mentioned in Table 1 given below:

Table 1. Constituents of mortar batches defined in AAR-2 [10].

\begin{tabular}{cc}
\hline \multicolumn{2}{c}{ Constituents } \\
\hline Cement $(\mathrm{g})$ & 400 \\
Fine aggregate $(\mathrm{g})$ & 900 \\
Water $(\mathrm{g})$ & 188 \\
Water/cement ratio & 0.47 \\
\hline
\end{tabular}

Cyprus is known to have one of the warmest climates in Europe. As a Mediterranean island, the annual average (actual) temperatures observed in Cyprus during the day and night are $24^{\circ} \mathrm{C}$ and $14^{\circ} \mathrm{C}$, respectively; where the apparent temperature felt during the day in summer period can go beyond $40^{\circ} \mathrm{C}$ frequently. The climatic conditions of Cyprus have caused the concrete industries of the island to generally prefer slow-hydrating blended cements with lower rates of heat of hydration.

CEM II / B-M (with 21-35\% supplementary cementitious materials (SCM)), which is the most typically used cement in North Cyprus, was chosen to test the potential alkali-silica reactivity of Cyprus aggregates used in concrete structures. CEM I, containing only cement clinker, was also used in this study as a control set, in order to verify the effect of SCM presence on the reactivity.

Therefore, a total of four mortar batches made of two different aggregates (from "North" and "South" Cyprus) and two different cements (CEM I and CEMII/B-M) were made for investigating the ASR occurrence likelihood in Cyprus.

\subsection{Exposure Conditions and Measurements}

Three mortar bars were made for each batch as proposed in the standard AAR-2 method, by using the materials with the proportions given in Table 1 . The samples were placed in moist cabinet at room temperature and $90 \%$ humidity for 24 hours. Then, the mortar bars were immersed in container with distilled water, sealed carefully and placed in thermal cabinet with $80^{\circ} \mathrm{C}$ for 24 hours. After measuring initial length of each mortar bar $\left(\mathrm{L}_{0}\right)$ after the first 24 hours, then the bars were immersed in $1 \mathrm{~N}$ sodium hydroxide and stored at $80^{\circ} \mathrm{C}$ for 14 days. During the testing period of 14 days, five comparator readings $(\mathrm{Ln})$, at 3rd, 6th, 9th, 12th and 14th days of experiment, were taken at the same time each testing day (age). Length change in the samples was measured with digital length comparator having $0.001 \mathrm{~mm}$ sensitivity. The total change in the length of each mortar bars were calculated using the below relationship:

$$
\text { Length change, } \%=\frac{L n-L 0}{\text { Gauge length }} \times 100
$$

Average of the length change observed in three bar samples were reported for each batch at each measurement age.

\section{Results and Discussions}

The results obtained in this preliminary study on the determination of alkali-silica reactivity of Cyprus aggregates are presented below in Fig. 1-4. Length change value presented for each age is the average obtained from three bars prepared for each batch. The error bars represent one standard deviation. "North" and "South" represents the crystallized dolomitic limestone aggregates from North Cyprus and diabase aggregates obtained from South Cyprus, 
respectively. The expansion limits defined by RILEM AAR-2 method for "Potentially reactive" and "Deleterious" behaviors, which are $0.1 \%$ and $0.2 \%$ respectively, are shown in each graph for reference.

\section{Length Change Behavior of Mortars Made with CEM I Under the Conditions of \\ AAR-2}

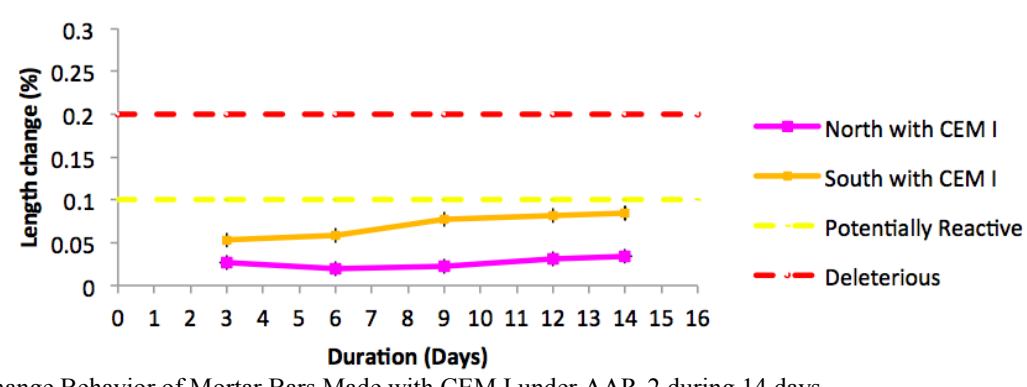

Fig. 1. Length Change Behavior of Mortar Bars Made with CEM I under AAR-2 during 14 days

\section{Length Change Behavior of Mortars Made with CEM II/B-M Under the Conditions of AAR-2}

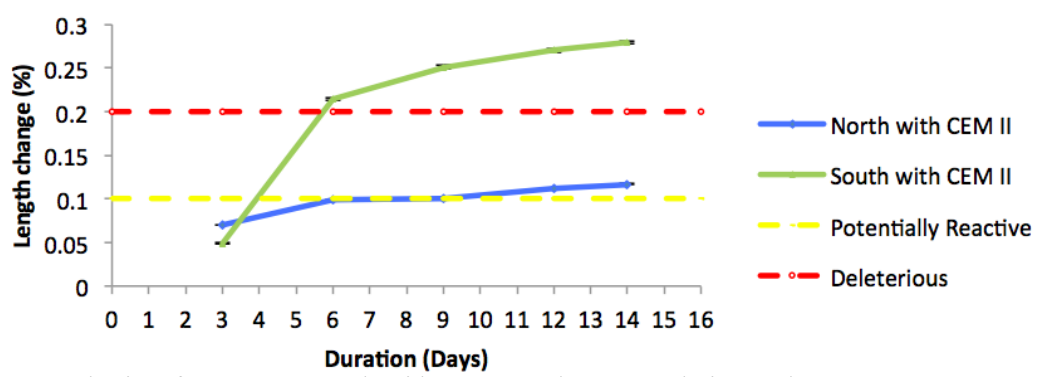

Fig. 2. Length Change Behavior of Mortar Bars Made with CEM II under AAR-2 during 14 days

In their work, Sims and Nixon [11] suggest the use the $0.1 \%$ and $0.2 \%$ length change limits for classifying "potentially reactive" and "deleterious" behaviors of mortar samples, respectively. These limits were defined based on studies carried out by RILEM on the aggregate combinations with previously known reactivity performances from different parts of the world [11].

Figure 1 illustrates the length change behavior of mortar bars made with "North" and "South aggregates in combination with CEM I type of cement which is defined by EN197-1 to contain only cement clinker, without any presence of supplementary cementitious materials (SCM). In the case of being used with CEM I, both "North" and "South" cements are observed to yield expansion values that are below the defined potentially reactive behavior limit. However, mortar bars made with "South" aggregates were observed to experience much higher expansion relative to the samples made with "North" samples. Nevertheless, both aggregates can be classified as "innocuous" in the case of being used in combination of this cement.

Figure 2 illustrates the length change behavior of with "North" and "South aggregates in combination with CEM II/ B$\mathrm{M}$ type of cement, which is defined by EN197-1 to contain 21-35\% of SCMs. These results indicate that the SCMs content of CEM II had increased the likelihood of ASR occurrence for both aggregates. The expansion recorded for mortar bars made with "South" aggregates were observed to exceed $0.2 \%$, which is the limit defined by Sims and Nixon [11] for "deleterious" alkali-silica reactivity behavior of aggregates. On the other hand, the mortar bars made with "North" aggregates was observed to experience a more gradual increase in length; the expansion recorded at the end of 14 days of testing period was observed to be slightly higher than $0.1 \%$, which is the limit defined for "potentially" reactive behavior of aggregates.

Fig. 3 and 4 provides a comparative information on the ASR potential of "South" and "North" aggregates, respectively, when they are used in combination with two different cements, namely CEM I and CEM II/ B-M. The latter cement is known to contain supplementary cementitious materials up to $35 \%$. In the case of both aggregates, the mortar batch prepared with CEM II/ B-M yields in more than three times of expansion than the one observed for mortars prepared with CEM I. 


\section{Length Change Behavior of Mortars Made with "South" Cyprus Aggregates Under the Conditions of AAR-2}

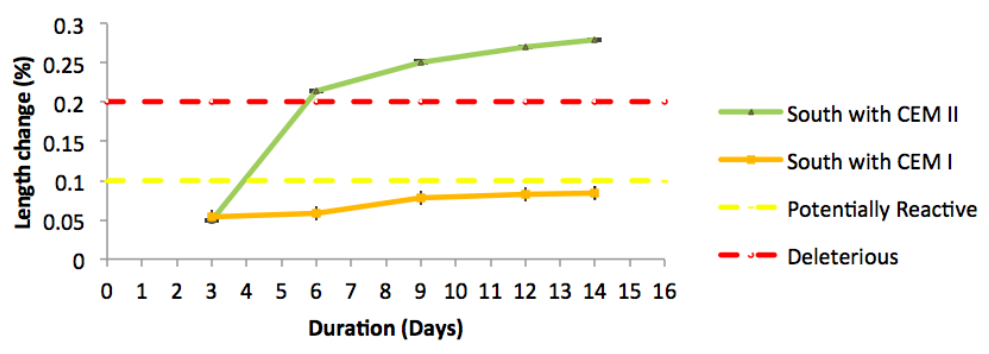

Fig. 3. Length Change Behavior of Mortar Bars Made with "South" Aggregate under AAR-2 during 14 days

\section{Length Change Behavior of Mortars Made with "North" Cyprus Aggregates Under the Conditions of}

AAR-2

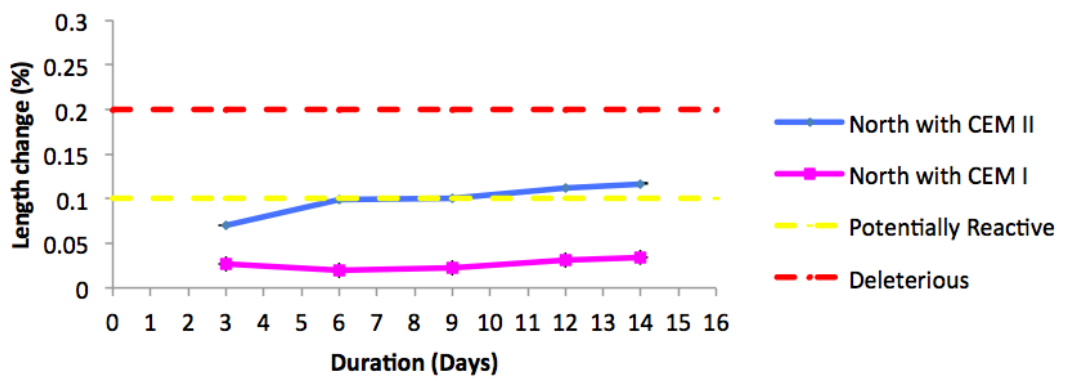

Fig. 4. Length Change Behavior of Mortar Bars Made with "North" Aggregate under AAR-2 Cyprus during 14 days.

Table 3. Preliminary results obtained with AAR-2 method on alkali-silica reactivity level of Cyprus aggregates

Batches Alkali-Silica Reactivity

"North" aggregates with CEM I

"North" aggregates with CEM II

“South" aggregates with CEM I

"South" aggregate with CEM II
Innocuous

Potentially reactive

Innocuous

Deleterious

Some of the previous studies in the related literature [12-15] suggest that SCM incorporation to the mix is an effective way for reducing the expansion and related damage in concrete elements as a result of ASR. Besides their effect on permeability of concrete, formation of $\mathrm{C}-\mathrm{S}-\mathrm{H}$ as a result of pozzolonic activities is known to incorporate alkalies and therefore, caused a reduced $\mathrm{pH}$ level, which reduces the occurrence of ASR [14,15]. However, the findings of this study indicate that CEM II/B-M could potentially increase the alkali-silica reactivity experienced by samples, which may imply an inadequate alkali-binding effect of SCMs incorporated in the cement. Kerkoff [16] suggests that the effectiveness of the supplementary cementitious materials in ASR mitigation should be tested first with accelerated mortar bar test and if their performance in reducing expansion is not observed to be successful (e.g. like in this study), then further investigations could optionally be carried out with concrete-prism test having longer testing periods, in 
order to be able to obtain more realistic information on the actual performance of cement- aggregates combinations used. In any case, Kerkoff [16] emphasized the importance of reducing concrete alkalies to a limit required to control ASR effectively, if SCM-containing cements are observed to fail to mitigate ASR. Kerkoff suggest that such an inadequate ASR mitigation performance of cementitious materials can be due to the "pessimum" effect of SCM dosage. In such a case SCM dosage that is lower than the optimum dosage is reported to potentially yield even higher ASRrelated expansion when compared to the performance of not SCM-containing cements [16].

Table 3 summarizes the ASR performance and the material combinations used four different batches tested in this preliminary study.

The findings presented in Table 3 have the potential to significantly influence practices of concrete industries in the island, mainly in North Cyprus. As mentioned before, CEM II/ B-M is the most widely used cement in North Cyprus for several decades, mainly due to its relatively slower rate of hydration, which is advantageous when the climatic condition of the island is considered. Higher temperature values are known to accelerate ASR [3,17]. Therefore, the hot climate of the island has the potential to favor an increased rate of alkali-silica reactivity. Since the combination of CEM II/B-M with "North" aggregates has been commonly used in concrete manufacture, then the existing structures in North Cyprus constructed decades ago with these materials might be potentially experiencing alkali-silica reaction.

The results provided for the diabase aggregates used in South Cyprus are in accordance with previous findings [8,9]. The result of this study indicates the critical importance of using the adequate cement type with the aggregates that are already suspected to exhibit alkali-silica reactivity, in order to prevent any future ASR-related damage in concrete structures in Cyprus.

\section{Conclusions and Recommendations}

This study provides preliminary results on the alkali-silica reactivity of North and South Cyprus aggregates obtained with The Ultra-Accelerated Mortar Bar Test Method (AAR-2) proposed by RILEM. With this study, the authors' aim was to provide fundamental information on the likelihood of ASR occurrence in concretes manufactured in Cyprus, which had not been extensively studied before in the island. Two types of cements were employed in the study; CEM II/ B-M with SCM content that is known to be preferred extensively by the concrete industries in the island, as well as CEM I containing only clinker that was employed as a control set in order to verify the effect of SCMs on the ASR performance of aggregates, were used. Preliminary results obtained in this study serves to draw the following conclusions:

a) The use CEM II/B-M yielded results indicating the risk of ASR occurrence for both North and South Cyprus aggregates. In the case of using this cement, "North" aggregates are observed to be "potentially reactive", where "South" aggregates are observed to exhibit "deleterious" behavior at the end of the testing period. The obtained results confirm and contribute to the limited information of the level of reactivity of South Cyprus aggregates in the related literature. The level of reactivity of the North Cyprus aggregates was investigated for the very first time with this study.

b) Majority of the concrete structures in North Cyprus are made with the combination of CEM II/B-M with crystallized dolomitic limestone aggregates, referred as "North" aggregates in this study. The "potentially reactive" behavior of this combination observed in this study implies the need for the concrete industry to re-consider the use of this type of cement with the locally available aggregates. The likelihood of ongoing ASR in the existing buildings should also be studied to verify any potential need to take precautions in order to prevent ASR-related damage that might become evident in the coming future.

c) The mortar batches prepared both with North and South Cyprus aggregates in combination with CEM I were observed to exhibit "innocuous" behavior for ASR. When compared with the performance of batches prepared with CEM I, the use of SCM-containing CEM II yielded more than three times of the length change in mortar bars exposed to AAR-2 conditions. This finding implies the importance of selection adequate cement type to be used with the locally available aggregates in order to minimize ASR-related expansion and consequent damage in structures.

d) The inadequate performance of SCM-containing CEMII/B-M cement in ASR mitigation should be further investigated; concrete prism test methods having longer testing periods and more realistic conditions can be employed to further investigate the ASR performance of the combination of Cyprus aggregates with this conventional cement used in the island. Further studies should also be carried out on the exact chemical composition of SCMs included in this cement type, in order to provide more insight on its level of alkali-binding characteristics in concrete.

e) Further studies on the alkali-silica reactivity of Cyprus aggregates should also be carried out with additional techniques such as SEM-EDX, in order to provide more detailed information on the actual cause of expansion observed in the samples; the detection of formed alkali-silica gel in the samples would be beneficial to confirm the reactivity of aggregates with a higher certainty.

\section{Acknowledgement}

The authors of this paper would like to acknowledge Dr. Mehmet Necdet from Geology and Mines Office in North Cyprus who facilitated the collaboration with the Geological Survey Department of Republic of Cyprus. Authors acknowledge the kind supports of both North and South Cyprus Departments in acquiring aggregate samples that are used in this study from the quarries in Beşparmak (Pentadaktylos) and Troodos Mountains, respectively. 


\section{References}

1. Y. Zhu, A. Zahedi, L.F.M. Sanchez, B. Fournier, S. Beauchemin, Overall assessment of alkali-silica reaction affected recycled concrete aggregate mixtures derived from construction and demolition waste, Cem. Concr. Res. 142, 106350 (2021)

2. A. Zahedi, C. Trottier, L. Sanchez, M. Noël, Microscopic Assessment of ASR-Affected Concrete Under Confinement Conditions, Cem Concr Res. 142, 106456 (2021)

3. B. Fournier, M. Bérubé, Alkali-Aggregate Reaction in Concrete: a Review of Basic Concepts and Engineering Implications, Can. J. Civ. Eng. 27, 167-191 (2000)

4. M. Thomas, K. Folliard, B. Fournier, P. Rivard, T. Drimalas, Methods for Evaluating and Treating ASR-Affected Structures: Results of Field Application and Demonstration Projects I, Report No. FHWA-HIF-14-0002, Federal Highway Administration, U. S. Department of Transportation, Washington, DC (2013)

5. A. Zahedi, L. Sanchez, M. Noël, Effect of Confinement on AAR-induced expansion and damage, $16^{\text {th }} I C A A R$ International Conference on Alkali Aggreg. React. Concr., Lisboa, Portugal (2020)

6. C. Trottier, R. Ziapour, A. Zahedi, L. Sanchez, F. Locati, Microscopic characterization of alkali-silica reaction (ASR) affected recycled concrete mixtures induced by reactive coarse and fine aggregates, Cem. Concr. Res. 144, $106426(2021)$

7. A. Zahedi, C. Trottier, L. Sanchez, M. Noël, Evaluation of Mechanical Properties of Alkali-Silica Reaction (ASR)-Affected Concrete Under Confinement Conditions, Cem. Concr. Compos. (2021)

8. G.M. Idorn, In concrete progress: from antiquity to third millennium book, Thomas Telford Ltd., London, UK (1997)

9. P.J. Nixon, I. Sims, RILEM TC106 alkali aggregate reaction - accelerated tests, $9^{\text {th }}$ International Conference on Alkali-Aggregate React. Concr., London, UK Reun. Int. Des Lab. Expert. Des Mater., pp. $70-100$ (1992)

10. T. 191-A. RILEM, AAR-2: detection of potential alkali-reactivity of aggregates-the ultra-accelerated mortar-bar test, Reunion Internationale des Laboratoires et Experts des Materiaux 5 (2000)

11. I. Sims, P. Nixon, RILEM recommended test method AAR-0: detection of alkali-reactivity potential in concreteoutline guide to the use of RILEM methods in assessments of aggregates for potential alkali-reactivity, Mater. Struct. 36, 472-479 (2003)

12. V.E. Saouma, Diagnosis \& Prognosis of AAR Affected Structures, State-of-the-Art Report of the RILEM Technical Committee 259-ISR (2020)

13. R. Johnson, M.H. Shehata, The efficacy of accelerated test methods to evaluate Alkali Silica Reactivity of Recycled Concrete Aggregates, Constr. Build. Mater. 112, 518-528 (2016)

14. A.M. Neville, Properties of Concrete, John Wiley \& Sons, New York (1996)

15. M.D.A. Thomas, The effect of supplementary cementing materials on alkali-silica reaction: a review, Cem. Concr. Res. 41, 1224-1231 (2011)

16. B. Kerkoff, Guide Specification for Concrete Subject to ASR, Concrete Bridge Views, U.S. Department of Transportation Fedaral Highway Administration, USA (2008)

17. M.P. K., M. M., Concrete- Structures, Properties and Materials, Prentice-Hall $2^{\text {nd }}$ Edition, USA (1993) 